\title{
DOUTRINAS DE SEGURANÇA NACIONAL: BANALIZANDO A VIOLÊNCIA
}

\author{
Cecília Maria Bouças Coimbra*
}

RESUMO. Este trabalho analisa historicamente o Brasil nos anos 60 e 70, apontando o fortalecimento/implementação da chamada Doutrina de Segurança Nacional na Escola Superior de Guerra. Apresenta algumas características do aparelho repressivo daquela época, colocando em análise alguns pontos da legislação de segurança nacional e do funcionamento da justiça militar. Finalizando, aponta a produção de uma nova Doutrina de Segurança Nacional que se fortaleceu nos anos 90, não mais contra os opositores políticos, mas contra os excluídos sociais, em especial.

Palavras-chaves: ditadura militar, violência, Brasil anos 70 e 90

\section{DOCTRINES OF NATIONAL SECURITY: VULGARIZING VIOLENCE}

ABSTRACT. This study analyses Brazil historically during the 60's and 70's, focusing on the strengthening/implementation of the so called National Security Doctrine emerged mainly from the Escola Superior de Guerra. It shows some characteristics of the repressive system from that period, analyzing some aspects of the national security laws, as well as the performance of the military justice. Finally, the study shows the production of a new National Security Doctrine, becoming stronger by the 90 's, no longer against political opposition, but especially against the socially excluded ones.

Key words: military dictatorship, violence, Brazil in the 70's and 90's.

* Psicóloga, professora da Universidade Federal Fluminense, Pós-Doutora em Ciência Política no Núcleo de Estudos de Violência da USP, Presidente do Grupo Tortura Nunca Mais/RJ, Presidente da Comissão de Direitos Humanos do Conselho Federal de Psicologia e membro do Conselho Consultivo do Centro de Justiça Global.

Endereço para correspondência: Rua Maranhão, 206 - Méier, CEP 20720-230, Rio de Janeiro-RJ. Telefax: (21) 899-0995. E-mail: gtnm@alternex.com.br

\begin{tabular}{|l|l|l|l|l|l|}
\hline Psicologia em Estudo & DP/CCH/UEM & v. 5 & n. 2 & p. 1-22 & 2000 \\
\hline
\end{tabular}




\section{INTRODUÇÃO}

Penso apresentar um sucinto quadro histórico do Brasil nos anos 60 e 70, no sentido de contextualizar o aparecimento e a implementação da chamada Doutrina de Segurança Nacional em nosso país. Para isto, apontarei algumas subjetividades produzidas/fortalecidas naqueles anos como cenário para as doutrinas que estavam sendo gestadas pelo regime militar, através, principalmente, da Escola Superior de Guerra. Utilizo aqui o conceito de subjetividade segundo o enfoque de Guattari (1988), não como coisa em si, essência imutável ou natureza, mas como formas de pensar, sentir, perceber e agir, produzidas por diferentes dispositivos sociais; ou seja, construídas no registro da história, do social.

A seguir, apresentarei e colocarei em análise algumas características do aparato repressivo que se vai criando e fortalecendo em nosso país, em alguns de seus órgãos, que vão se tornando, muitos deles, verdadeiros Estados dentro do Estado. Também serão apontadas algumas técnicas repressivas que vão se sofisticando, no Brasil, no início da década de 70, chegando a ser exportadas para outras ditaduras latinoamericanas, como por exemplo a figura do desaparecido político.

Finalizando, penso trazer, mesmo que rapidamente, a produção de uma nova Doutrina de Segurança Nacional, que se gesta e se fortalece desde o início dos anos 90, no Brasil e em toda a América Latina. Ou seja, como sob novas maquiagens e utilizando as mesmas estratégias, os discursos de segurança pública ainda estão profundamente influenciados pela Doutrina de Segurança Nacional vigente nas décadas de 60 e 70.

\section{A GESTAÇÃO DO GOLPE MILITAR DE $1964^{1}$}

O período 1946/1964 representa em nossa história uma etapa de conflitos que geraram modificações profundas em toda a sociedade brasileira.

A maestria política de Getúlio Vargas havia lançado as bases de um novo fenômeno na vida política nacional: o populismo. Nele era estimulada a mobilização das massas, mas em um contexto em que as

As informações desta parte histórica foram retiradas da Arquidiocese de São Paulo (1985a). 
energias acabavam sendo capturadas e capitalizadas pelos diferentes poderes.

Aquele período também caracterizou-se pela forte desnacionalização, quando disposições legais sobre política alfandegária abriram as comportas à penetração do capital estrangeiro, notadamente o norte-americano.

Com o governo eleito de Vargas (1950/1954), o embrião do golpe militar de 1964 começava a criar corpo. Seu mandato esteve voltado para uma vacilante defesa do nacionalismo econômico, o que acirrou o ódio de setores mais conservadores ligados aos capitais estrangeiros, já em íntima aliança com a doutrina que se forjava na Escola Superior de Guerra.

Fortalecendo posturas populistas e sem base de apoio nos setores mais à esquerda, esta política abriu a porta para ações golpistas que, dessa forma, fizeram sua primeira tentativa, dez anos antes do êxito alcançado em 1964.

Tramou-se a deposição de Getúlio através de campanhas que levantaram, nos quartéis e nos segmentos mais conservadores da sociedade brasileira, o fantasma da política trabalhista então vigente. $\mathrm{O}$ golpe de Estado já se encontrava a caminho, comandado pelos chefes militares, quando foi freado pelo gesto dramático de Getúlio: o seu suicídio.

Até 1956, quando foi empossado o novo presidente Juscelino Kubitschek, o país viveu momentos conturbados por novas tentativas dos mesmos setores golpistas que esbarraram na resistência de grupos nacionalistas das Forças Armadas, detentores de postos importantes, naquele período. O Ministro da Guerra, Henrique Teixeira Lott, por exemplo, desempenhou papel importante na manutenção da legalidade constitucional, à época. Os golpistas voltaram-se, mais uma vez, para a fase dos preparativos, sempre aglomerados em torno da Escola Superior de Guerra.

Durante o Governo de Juscelino (1956/1960) alguns setores golpistas ocuparam a cena: em fevereiro de 1956, com o levante de Jacareacanga, e em dezembro de 1959, com a rebelião de Aragarças. Esta última foi liderada pelo então tenente-coronel João Paulo Moreira Burnier, que se caracterizaria, após o golpe militar de 1964, como torturador de presos políticos, sendo apontado como um dos assassinos do desaparecido político Stuart Angel Jones.

Uma nova tentativa golpista ocorreu quando, em 1961, Jânio Quadros, que havia sido eleito (1960), renunciou à Presidência da 
República. Seu vice, João Goulart, herdeiro do nacionalismo getulista, estigmatizado como radical pela maioria da alta hierarquia militar, teve seu nome impugnado para ocupar o cargo de Presidente. Os três ministros militares alardeavam que não aceitavam a posse de Goulart. Seguiu-se ampla movimentação em todo o país, sendo que o então governador do Rio Grande do Sul, Leonel Brizola, teve um papel de destaque na mobilização popular contra o golpe que se tramava. Recuaram os militares, impondo o estabelecimento do regime parlamentarista no Brasil, encontrando, com isso, uma forma de manietar as pretensões reformistas de João Goulart.

Os anos de 1962 a 1964 foram palco de rápido crescimento das lutas populares em nosso país. Goulart encampou numerosas bandeiras levantadas pelos trabalhadores desde o fim do Estado Novo. A aceleração da chamada "política de reformas de base" deu-se a partir de janeiro de 1963, quando o presidente conseguiu, através de um plebiscito que lhe deu esmagadora vitória, derrubar o parlamentarismo imposto pelos militares, voltando a governar sob o sistema presidencialista.

Os trabalhadores, ao arrepio da estrutura sindical que a lei impunha desde Getúlio, criaram uma central sindical, o Comando Geral dos Trabalhadores (CGT). Esta passou a ser produzida pelos conservadores como um espantalho que comprovava a iminência de uma revolução comunista no Brasil.

Aqueles anos caracterizaram-se pela ascensão dos movimentos sociais, que, com o consentimento e o apoio governamentais, voltaram-se para a "conscientização popular".

A efervescência política, o intenso clima de mobilização $e$ os avanços na modernização, industrialização $e$ urbanização que configuravam aquele período traziam , necessariamente as preocupações com a participação popular (Coimbra, 1995, p. 3).

Este engajamento traduzia-se não só pelo fortalecimento do CGT, mas pela ascensão do movimento estudantil e das lutas camponesas. A União Nacional dos Estudantes (UNE), por exemplo, através de sua UNE/Volante, levava para diferentes estados brasileiros vários shows e peças de teatro que falavam das chamadas "reformas de base". No Nordeste, Francisco Julião e as Ligas Camponesas - que se espalhavam 
por 20 estados - incendiavam os camponeses com sonhos de liberdade e de reforma agrária.

Diferentes experiências com alfabetização de adultos foram levadas a cabo: o Movimento de Cultura Popular (MCP), em Pernambuco, e o Programa Nacional de Alfabetização, que utilizava o método Paulo Freire, também em Pernambuco e no Rio de Janeiro.

Agitavam-se em todo o país as bandeiras das "reformas de base". Também no âmbito parlamentar estruturou-se uma frente nacionalista que fez crescerem as pressões no sentido das reformas.

Antes que todo esse clima de efervescência atingisse limites revolucionários, os conservadores desencadearam ampla agitação golpista, a qual era estimulada claramente pelo governo norte-americano, assustado pelas bandeiras nacionalistas. O "pacto populista" entre o governo de João Goulart e os setores populares começava a se tomar perigoso para a expansão do capital estrangeiro. A situação crítica da economia brasileira, com inflação galopante, crises de recessão e o fantasma da comunização propiciavam a propaganda, junto às classes médias, da necessidade de um governo forte.

Neste quadro deu-se o golpe militar de 1964, quando as forças armadas ocuparam o Estado, para servirem aos interesses dos capitais estrangeiros.

\section{O GOLPE DENTRO DO GOLPE: O TERRORISMO DE ESTADO}

No período de 1964 a 1969, apesar das centenas de cassações, prisões e torturas, com relação à produção da época, não houve impedimento de sua circulação ${ }^{2}$. Era a ditadura, mas havia uma hegemonia cultural da esquerda; entretanto, a circulação de tais idéias era totalmente bloqueada às classes populares. Passava a ser realizada num circuito fechado e "(...) integrada ao sistema - teatro, cinema, disco e a ser consumida por um público já 'convertido 'de intelectuais e estudantes de classe média" (Hollanda, 1978, p. 33).

Foi o circuito do espetáculo que passou a funcionar e, apesar da ditadura, produziram-se territórios singulares ${ }^{3}$. Por exemplo, os shows

Sobre o assunto consultar SCHWARZ (1978)

3 Segundo F. Guattari, processos de singularização designam os processos disruptores no campo da produção de desejo; trata-se de movimentos de protesto do inconsciente 
"Opinião", "Arena Canta Zumbi", "Roda Viva", "O Rei da Vela", os festivais de Música Popular Brasileira em circuitos universitários inauguraram a chamada "canção de protesto". O Cinema Novo, o movimento Tropicalista, a revista Civilização Brasileira - de 65 a 69, pólo de concentração da intelectualidade de esquerda - engrossaram o caldo de cultura que explodiu em 1968.

A geração de 68 trouxe, além da contestação política, a marca dos movimentos contraculturais: a recusa aos padrões de bom comportamento e a crença na política, segundo as quais "(...) tudo deve se submeter ao político, o amor, o sexo, a cultura, o comportamento; era difícil ser indiferente naqueles tempos apaixonados" (Ventura, 1988, p. 75).

Dentro do segmento dirigente que havia dado o golpe, já em 1964 começavam a surgir divisões: a ala representada por Castelo Branco ( $1^{\circ}$ presidente militar) e uma outra, que ficou conhecida como "linha dura". Esta propugnava a radicalização e o avanço das medidas repressivas, principalmente quando iniciou sua ascensão, em 1967, quando da sucessão de Castelo Branco. O nome apoiado por ela, Costa e Silva, tornou-se o $2^{\circ}$ presidente militar.

Um mês antes da posse, em fevereiro, caminhando para a radicalização, foi imposta a nova Lei de Imprensa e a nova Lei de Segurança Nacional, que será rapidamente abordada no item seguinte. Quanto à Lei de Imprensa, restringia profundamente o direito de crítica e previa condenações de até 10 anos para os infratores de seus dispositivos penais.

Os anos de 67 e 68, portanto, marcaram o crescimento das dissidências entre as forças que apoiaram o golpe. À época, foi articulada por Lacerda - já cassado - Frente Ampla de Oposição, que recebeu o apoio de Kubitschek e do próprio Goulart - ambos também cassados e o último no exílio.

A oposição ao regime também ganhava força nas ruas, nas fábricas e nas universidades. Desde 1966 a UNE retomou suas atividades, e em março de 1968 a polícia reprimiu uma manifestação de estudantes, matando o secundarista Edson Luiz, no Rio. Era a faísca que faltava. Nos meses seguintes alastraram-se, nas principais capitais do país, as manifestações de estudantes, intelectuais, operários. Em julho, no Rio de Janeiro, ocorreu a Passeata dos Cem Mil, e em outubro o célebre

contra as subjetividades apitalísticas através da afirmação de outras maneiras de ser, outras sensibilidades, outras percepções, etc. Em Guattari e Rolnik (1988) 
congresso clandestino da UNE, em Ibiúna (SP), foi estourado pela polícia, quando cerca de 700 estudantes foram presos.

As lutas operárias também apareciam, e desde 66/67 pequenas paralisações foram realizadas isoladamente. Em 1968, duas importantes greves aconteceram: Contagem (MG) e Osasco (SP), as quais foram violentamente reprimidas.

A repressão agia, em 1968, de forma cada vez mais violenta, com o apoio de grupos paramilitares: "Bombas em teatros do Rio e São Paulo, em editoras, jornais, espaços culturais, faculdades (...); seqüestros e espancamentos de artistas e estudantes" (Reis Filho, 1988, p. 30). Foi denunciado no próprio Parlamento o envolvimento e a utilização de uma tropa de elite da Aeronáutica (o Parasar) na prática de missões criminosas. O Ministro da Aeronáutica, o tristemente famoso brigadeiro Burnier, desmentiu o fato, mas vários oficiais do Parasar confirmaram, tendo sido presos e afastados de suas funções.

Estava armada a cena para a vitória da "linha dura". O golpe dentro do golpe veio com a edição do Ato Institucional n. ${ }^{\circ}$, de 13 de dezembro de 1968, que instituiu a ditadura sem disfarces: o terrorismo de Estado.

A partir daí, o regime militar consolidou a sua forma mais brutal de atuação, através de uma série de medidas, como o fortalecimento do aparato repressivo, com base na Doutrina de Segurança Nacional. Desta forma, estava garantido o desenvolvimento econômico, com a crescente internacionalização da economia brasileira e a devida eliminação das "oposições internas". Silenciava-se e massacrava-se toda e qualquer pessoa que ousasse levantar a voz.

\section{OS ANOS DE CHUMBO: A ESCOLA SUPERIOR DE GUERRA, A DOUTRINA DE SEGURANÇA NACIONAL E O APARATO REPRESSIVO}

O AI-5 inaugurou também o governo Médici (1969/1974) - $3^{\circ}$ presidente militar -, um dos mais violentos e repressivos períodos de toda a história da República. Representante da "linha dura", Emílio Garrastazu Médici governou sob o lema "segurança e desenvolvimento nacionais". Ao lado da repressão, que cada vez se sofisticava mais, o país viveu a fase do "milagre econômico", dos projetos de impacto, das obras faraônicas, como a Transamazônica e a ponte Rio-Niterói, o que 
fortalecia uma propaganda permanente e bem elaborada do Estado forte, que massacrava no nascedouro todas as modalidades de lutas populares, fossem de reivindicação salarial ou de denúncia de violação dos direitos humanos.

Vendia-se massivamente a imagem do Brasil como a "ilha de tranqüilidade", de "progresso", de "bem-estar" e de euforia. Vivia-se um clima de ufanismo, com a classe média ascendendo e aproveitando-se das sobras do "milagre". Ao som do pregão das Bolsas de Valores e do slogan "Brasil: ame-o ou deixe-o", a ascendente classe média vivia momentos inesquecíveis de consumismo, com a "modernização", levada ao ritmo de "Brasil Grande". "A televisão passou a alcançar um nível de eficiência internacional, fornecendo valores e padrões para 'um país que vai para frente' " (Hollanda, 1978, p. 125). Foi o inicio do reinado da Rede Globo, da aldeia global, que se fortaleceu gradativamente naquele período, produzindo/fortalecendo subjetividades então hegemônicas: formas de pensar, sentir, perceber e agir condizentes com o regime. Tais processos traduziam-se na importância dada ao consumismo, à necessidade de se ascender socialmente; "subir na vida" tornava-se a palavra de ordem. Foi produzida uma aceitação quase unânime das regras do sistema: a população passava a aceitar passivamente que compete ao governo a resolução dos problemas; a ela, compete trabalhar e/ou estudar e não se imiscuir em política.

\section{A Escola Superior de Guerra}

Ao lado dessas produções vivia-se no Brasil um dos mais violentos períodos de perseguições, seqüestros, torturas, mortes e desaparecimentos de opositores políticos. Expandia-se a doutrina do regime militar, baseada na segurança nacional, tendo como centro irradiador a Escola Superior de Guerra, que ajudou no avanço e no desenvolvimento de diferentes órgãos repressivos.

A Escola Superior de Guerra (ESG), fundada em 1949 - à época da II Guerra Mundial -, desde seu início esposou o anti-comunismo.

A estreita vinculação surgida entre oficiais brasileiros que lá estavam, como Castello Branco, Golbery do Couto e Silva e outros, e seus colegas norte-americanos chegou até mesmo a fazer com que compartilhassem a expectativa de continuação da guerra ou início de uma 
terceira - opondo desta vez União Soviética e os aliados ocidentais (...). Terminada a guerra, toda essa geração de oficiais, em fluxo maciço, passou a freqüentar cursos militares americanos (...). Quando começam a retornar ao Brasil já estavam profundamente influenciados por uma nova concepção a respeito de como entender a Defesa Nacional. Nas escolas americanas tinham aprendido que não se tratava mais de fortalecer o Poder Nacional contra eventuais ataques externos, e sim contra um "inimigo interno", que procurava solapar as instituições (Arquidiocese de São Paulo, 1985a, p. 5354).

A ESG ficou sob jurisdição do Estado Maior das Forças Armadas e devia, em tese, ser dirigida por um oficial-general escolhido em rodízio entre as três Armas. Após 64, no entanto, só teve comandantes extraídos do Exército, o que aponta a hegemonia dessa Arma na condução do regime militar. Somente em 1978, quando do período de dissensão "lenta, gradual e segura", durante o governo Geisel (1974/1978), o rodízio foi retomado.

A ESG saiu vitoriosa em 1964 e, a partir daí, passou a funcionar como formadora de quadros para a administração do novo regime.

A seleção dos novos estagiários passou a seguir critérios rígidos. No caso de militares, a escolha dependia de recomendação dos superiores, que, por sua vez, baseavase no grau de identificação do candidato com as diretrizes do governo militar. Os civis eram escolhidos entre expoentes da "intelligentzia" alinhada com o regime, especialmente parlamentares governistas, oposicionistas moderados, professores universitários $e$ nomes emergentes entre o empresariado e a tecnocracia (Arquidiocese de São Paulo, 1985a, p. 56-57).

Através da Escola Superior de Guerra foi irradiada a Doutrina de Segurança Nacional, cuja principal fonte foi o livro de Golbery do Couto e Silva, publicado em 1967. 


\section{A Doutrina de Segurança Nacional e os aparatos de repressão}

O ponto de partida da Doutrina de Segurança Nacional foi a revisão do conceito de "defesa nacional". Concebido tradicionalmente como proteção de fronteiras contra eventuais ataques externos, este conceito, ao final dos anos 50, mudou para uma nova doutrina: a luta contra o inimigo principal, as "forças internas de agitação". Esta revisão apoiava-se na bipolarização do mundo advinda com a chamada "guerra fria". De um lado, os alinhados com a "democracia": os Estados Unidos e seus aliados; de outro, os comprometidos com o "comunismo internacional": a União Soviética, os países "satélites" e " os comunistas".

O "inimigo interno" era assim definido, nas palavras do General Breno Borges Fortes, comandante do Estado Maior do Exército, em discurso pronunciado na $10^{a}$ Conferência dos Exércitos Americanos, realizada em Caracas, em 1973:

O inimigo (...) usa mimetismo, se adapta a qualquer ambiente e usa todos os meios, lícitos e ilícitos, para lograr seus objetivos. Ele se disfarça de sacerdote ou professor, de aluno ou de camponês, de vigilante defensor da democracia ou de intelectual avançado, (...); vai ao campo e às escolas, às fábricas e às igrejas, à cátedra e à magistratura (...); enfim, desempenhará qualquer papel que considerar conveniente para enganar, mentir e conquistar a boa fé dos povos ocidentais. Daí porque a preocupação dos Exércitos em termos de segurança do continente deve consistir na manutenção da segurança interna frente ao inimigo principal; este inimigo, para o Brasil, continua sendo a subversão provocada e alimentada pelo movimento comunista internaciona. (Jornal da Tarde, 1973, p. 10).

Segundo Golbery, a Doutrina de Segurança Nacional fazia uma comparação entre segurança e bem-estar social. Ou seja, se a "segurança nacional" está ameaçada, justifica-se o sacrifício do bem-estar social, que seria a limitação da liberdade, das garantias constitucionais, dos direitos da pessoa humana. Foram estes princípios de "segurança nacional" que nortearam a subjetividade oficial em vigor à época: a caça ao "inimigo 
interno". Para isto, foi amplamente modificado o sistema de segurança do Estado brasileiro.

Duas foram as características dessas mudanças. Uma foi o gigantismo, a contínua proliferação de órgãos. Outra foi a atribuição de uma autonomia à operatividade dos organismos criados, que levou a se considerar, já no princípio da década de 70, a existência de um verdadeiro Estado dentro do Estado(...) Na primeira etapa de sua escalada repressiva, o regime se limitou a hipertrofiar os órgãos de repressão política já existentes antes de 64 . Mais tarde, (...) nas mais diferentes áreas, passou-se à criação de organismos mais adaptados (...), dotados às vezes de estrutura semi-clandestina e orientados para não inibir sua ação repressiva perante nenhum dos clássicos institutos jurídicos de proteção à pessoa humana (Arquidiocese de São Paulo, 1985a, p. 67).

Em abril de 1964 foi criado o Grupo Permanente de Mobilização Industrial (GPMI), instrumento para adaptar o poderio bélico das forças armadas à nova doutrina de segurança, que já considerava deflagrada a "guerra revolucionária" contra o "inimigo" infiltrado em todo o país. Congregavam-se militares e industriais para ampliar e modificar o sistema de segurança do Estado brasileiro.

Foi criada toda uma máquina para "produção e operação de informações", com o nome de Sistema Nacional de Informações, que poderia ser visualizado como uma pirâmide, que tinha como base as câmaras de torturas e os interrogatórios, e no vértice, o Conselho de Segurança Nacional (CSN). Este era presidido pelo General Presidente, tendo como secretário-geral o chefe da Casa Militar da Presidência da República.

Para coordenar os trabalhos do Conselho de Segurança Nacional foi criado, em 13 de junho de 1964, o Serviço Nacional de Informações (SNI), que teve suas atividades espalhadas por todo o território brasileiro. Para lá eram enviados os diplomados pela Escola Superior de Guerra, a qual

(...) em 1972 foi instalada, com finalidade exclusiva de preparar pessoal para o trabalho no SNI, a Escola 
Superior Nacional de Informações, que surgiu de um antigo curso oferecido pela ESG e ministrava cursos regulares sobre informações, voltando-se para a criação de especialistas em análise e coleta de informações. Ministrou também cursos rápidos para estagiários, sendo mais freqüentados aqueles destinados aos militares que iam servir como adidos nas embaixadas e aos funcionários dos serviços de segurança dos ministérios civis (Arquidiocese de São Paulo, 1985a, p. 70).

Foi no decorrer do governo Médici que as funções e prerrogativas do SNI aumentaram significativamente e se verificou sua militarização. Cresceu a tal ponto que se transformou na quarta Força Armada, embora não uniformizada. Foi o órgão de repressão mais importante, dentro e fora do Brasil, tendo agências em cada Ministério, empresa estatal e privada, universidade, governo estadual e municipal.

De 1967 a 1972 criaram-se inúmeros outros aparelhos repressivos. Em 1967 foi organizado o Centro de Informações do Exército (CIE), e em 1970 o da Aeronáutica (CISA) . O da Marinha, CENIMAR, que já existia antes de 1964, foi reestruturado em 1971.

O regime passou a se preocupar com uma maior integração entre os organismos repressivos já existentes. Esta deveria ser efetivada sob a hegemonia do Exército, não somente por ser a Arma de maior contingente, mas também porque a Doutrina de Segurança Nacional conferia-lhe papel especial na nova concepção de guerra, contra um "inimigo interno", e envolvendo especialmente forças terrestres.

Essa integração foi testada, em julho de 1969, com a criação, em São Paulo, da OBAN (Operação Bandeirantes), que se nutriu de verbas fornecidas por multinacionais, como o Grupo Ultra, Ford, General Motors. Foi estruturada com três tipos de equipes: de buscas, de interrogatório e de análise, as quais se revezavam, num trabalho ininterrupto, por turnos de 24 horas. Foi composta com efetivos do Exército, Marinha, Aeronáutica, DOPS (polícia política estadual), polícias federal, civil e militar; ou seja, todos os tipos de organismos de segurança e policiamento, chegando a contar com oficiais do Corpo de Bombeiros.

A "luta contra a subversão", em São Paulo, atingiu tantos êxitos que, em janeiro de 1970, formalizava-se a criação dos DOI-CODIs (Destacamento de Operações Internas / Centro de Operações de Defesa 
Interna) em cada região militar do país. Vinculados ao Exército, os DOICODIs passaram a dispor do comando efetivo sobre todos os organismos de segurança existentes na área. Cada DOI-CODI também se estruturou com o mesmo funcionamento que havia vigorado na OBAN, sendo comandado por oficial do Exército e com os mesmos efetivos - todos os tipos de organismos de segurança e policiamento.

Além de todos esses órgãos legais e oficiais, o Sistema Nacional de Informações, também conhecido como "Comunidade de Informações", contou com a cooperação de outros órgãos paramilitares, alguns mantendo atividades legais, como camuflagem, e outros inteiramente clandestinos. Ficaram tristemente famosos a Sociedade Brasileira de Defesa da Tradição, Família e Propriedade (TFP), o Comando de Caça aos Comunistas (CCC), o Movimento Anticomunista (MAC), a Facção Anticomunista (FAC), a Vanguarda Anticomunista, o Grupo Anticomunista, a Ação Anticomunista Brasileira e a Falange Pátria Nossa, muitos surgidos antes de 1964 e extremamente atuantes após o golpe.

Cabe registrar que a ação desse intrincado aparato de repressão não se circunscreveu às fronteiras do Brasil. Nos golpes militares ocorridos na Bolívia (1972), no Chile e Uruguai (1973) e na Argentina (1976), estiveram presentes oficiais e policiais brasileiros, participando ativamente de torturas e interrogatórios. Posteriormente, executaram "trabalhos" conjuntos com os serviços de informações e segurança desses países, mantendo uma rede para prisões, seqüestros, mortes e desaparecimentos de opositores políticos ${ }^{4}$.

\section{A LEGISLAÇÃO DE SEGURANÇA NACIONAL E A JUSTIÇA MILITAR}

A legislação de segurança nacional foi a expressão dessa doutrina, articulada e colocada em prática pelo regime militar. Ela foi transformada entre nós em preceito constitucional pela Emenda $n^{\circ} 1169$, que subverteu o direito público brasileiro, anulou os poderes constitucionais do Legislativo, subjugando a sociedade e os estabelecimentos político-jurídicos.

Foi a tristemente famosa “Operação Condor”. Sobre o assunto, consultar Mariano (1998) 
Criou-se, verdadeiramente, um Estado de Segurança Nacional, que emergiu, quer pelos Atos Institucionais, quer pela Constituição de janeiro de 1967, e que "aperfeiçoou" o conceito de segurança nacional.

Por esta Constituição, o Poder Executivo ficou com as principais atribuições da segurança nacional, possibilitando ao Presidente da República, ad referendum do Congresso Nacional, em casos de urgência, expedir decretos-leis sobre temas de segurança nacional. Ampliaram-se também os poderes e as atribuições do Conselho de Segurança Nacional e das Forças Armadas.

A Emenda Constitucional de n. ${ }^{\circ}$ de 1969 aprofundou e radicalizou todos os poderes já conferidos ao Executivo, ao Conselho de Segurança Nacional e às Forças Armadas, pela Constituição de 67. A Doutrina de Segurança Nacional projetou leis e regras sobre todos os setores da vida nacional ${ }^{5}$.

Através do Conselho de Segurança Nacional, entidade máxima do regime, foram traçados os 'objetivos nacionais permanentes' $e$ as 'bases para a política nacional' e, de acordo com esses objetivos, foram editados, pelo Poder Executivo, decretos, decretos-lei, atos institucionais, e apresentados ao Parlamento projetos de lei e emendas constitucionais; quando necessário, foram editados, até mesmo, os 'Decretos Secretos' (Arquidiocese de São Paulo, 1985a, p. 82).

A primeira Lei de Segurança Nacional foi editada em fevereiro de 1967, quando dos primeiros avanços da "linha dura" em nosso país. Prevaleceu sobre todas as leis e mesmo sobre a Carta Magna, propugnando que todos os "antagonismos" deveriam ser puníveis como crimes contra a segurança do Estado.

Até outubro de 1965, os atingidos pela atividade repressiva ainda tinham a possibilidade de recorrer à Justiça Comum e ao Supremo Tribunal Federal (STF). Com a edição do Ato Institucional n. ${ }^{\circ}$ 2, a Justiça Militar passou a monopolizar a competência para processar e julgar todos os crimes contra a Segurança Nacional. Os inquéritos policiais militares passaram a ser encaminhados às auditorias militares e regidos pelo Código de Justiça Militar.

5 Sobre o assunto, consultar Arquidiocese de São Paulo (1985 b). 
Vigorou a lógica - invertendo qualquer principio jurídico - de escolher sempre a interpretação mais desfavorável às pessoas acusadas de oposição política ao regime, de contrariar expressamente os dispositivos legais que lhes fossem favoráveis. Estas arbitrariedades estiveram presentes em todos os passos do procedimento jurídico, desde a instalação do inquérito até o fim do processo, com o julgamento.

O Projeto "Brasil Nunca Mais", coordenado pela Arquidiocese de São Paulo ${ }^{6}$, que está registrado em 12 volumes, foi o resultado de uma pesquisa realizada em todos os processos constantes no Supremo Tribunal Militar, no período de abril de 1964 a maio de 1979, que diziam respeito aos chamados "crimes contra a segurança nacional". Esta pesquisa selecionou 20 casos, que ilustram, de modo bastante representativo, a postura da Justiça Militar ao julgar processos instaurados contra os chamados "inimigos internos" do regime.

Esses casos apontam como a justiça brasileira - transformada simplesmente em justiça militar para todos os casos vinculados à segurança do Estado - estava totalmente atravessada pela Doutrina de Segurança Nacional, então vigente em nosso país.

Entretanto, apesar de todos esses dispositivos legais e jurídicos acoplados à "segurança nacional", denúncias foram feitas nas auditorias militares pelos milhares de presos políticos, denúncias estas que estão oficialmente registradas nos Inquéritos Policiais Militares (IPM's). Levantou-se que 1.843 pessoas presas no período de 1964 a 1979 denunciaram torturas, mortes e desaparecimentos de opositores políticos. Chegou-se, ainda, ao número de 7.727 pessoas denunciadas pela Justiça Militar no período de 1964 até 1979. Daí, calcula-se que o número de presos seja mais alto, pois muitos não foram denunciados e nem sequer prestaram depoimentos em auditorias militares ${ }^{7}$.

Quando terminou o último ano de Geisel (ainda em 1978), o saldo de repressões efetuadas pelo regime desde 64 já computava $10 \mathrm{mil}$ exilados políticos, 4.682 cassados por vários meios, milhares de cidadãos que passaram pelos cárceres políticos, centenas de mortos,

6 Esta pesquisa - cuja síntese é o livro "Brasil Nunca Mais", editado pela Vozes, em 1985 - consta de 12 volumes. Somente existem 25 exemplares desses volumes, que foram doados a entidades de direitos humanos e universidades no Brasil e no exterior.

7 Sobre o assunto, consultar Arquidiocese de São Paulo (1985 c). 
"desaparecidos", 245 estudantes expulsos da Universidade por força do decreto 477 (Arquidiocese de São Paulo, 1985a, p. 49)

\section{ANOS 90: UMA OUTRA DOUTRINA DE SEGURANÇA NACIONAL}

Na década de 90, muitos aspectos de todo esse "entulho" autoritário têm sido criticados e até mesmo superados, com relação aos aparatos de repressão, aos organismos de informação, à legislação repressiva e à justiça militar.

Entretanto, alguns permanecem sendo utilizados, sob novas maquiagens porém utilizando as mesmas estratégias.

Abordarei aqui apenas dois desses aspectos, embora muitos outros continuem existindo.

Com relação à Doutrina de Segurança Nacional, hoje, dentro da nova ordem mundial, dos projetos neo-liberais vigentes em escala planetária, os "inimigos internos do regime" - aqueles tratados como taispassam a ser os segmentos mais pauperizados e não mais somente os opositores políticos. São todos aqueles que os "mantenedores da ordem" consideram "suspeitos" e que devem, portanto, ser vigiados e, se necessário, eliminados. Grupos de extermínios - nascidos sob o beneplácito do regime militar e dele fazendo parte - funcionam hoje para estes fins, financiados por comerciantes e empresários, e com auxílio de muitos dispositivos sociais, como a mídia, e têm fortalecido subjetividades que produzem juízes e autores como sujeitos necessários à "limpeza" do corpo social, considerado enfermo. Estes enfermos são percebidos como perigosos e ameaçadores. A modernidade exige cidades limpas, assépticas, onde a miséria - já que não pode ser mais escondida e/ou administrada - deve ser eliminada. Eliminação não pela sua superação, mas pelo extermínio daqueles que incomodam os "olhos, ouvidos e narizes" das classes mais abastadas ${ }^{8}$.

As formas como a mídia produz o real, verdades, fantasias, dentre outras questões, também atravessam os temas sobre a violência atual,

8 Sobre o assunto, consultar Coimbra (1998). 
quando estão sendo marcados e identificados, por esses mesmos meios de comunicação, os suspeitos, os discrimináveis, os perigosos, os infames.

Produz-se um raciocínio linear, de causa e efeito, de que onde se encontra a pobreza está a marginalidade, a criminalidade, o perigo. Assim, também os 'mass-media' têm exercido papel importante como produtores da imagem do crime, do criminoso e dos locais perigosos.

Pesquisa realizada por Baratta (1993), em Saarbrücken (Alemanha), afirma que

(...) o alarme social e o medo da criminalidade estão relacionados sobretudo ao 'estereótipo criminoso' presente no senso comum, que é fortemente sustentado pelos meios de comunicação de massa. (Portanto), a criminalidade não é um 'dado natural': Ela é 'socialmente construída' através de processos de comunicação social e de mecanismos seletivos das reações sociais e oficiais (Baratta, 1993, p. 14-15).

Esta pesquisa vai nos apontar que, justamente pelos serviços prestados, dentre outros, pela mídia, a criminalidade ocupa um lugar desproporcionalmente alto na percepção do público, desviando a atenção dos problemas estruturais que geram essa própria criminalidade. Assinala, ainda, o caráter de produção da imagem da criminalidade, da insegurança urbana, do medo do crime e, especialmente, do estereótipo do criminoso. Tais construções, sem dúvida, têm servido para contribuir e tornar mais aceitáveis a desigualdade social, a pobreza e a miséria em que vivem enormes contingentes de nossa população. Portanto, as notícias veiculadas nos diferentes meios de comunicação de massa produzem/reproduzem/fortalecem tais rótulos e identidades. Não é por acaso que boa parte dos crimes contra a população pobre são encontrados nas seções policiais, pois nelas é que são veiculadas as notícias sobre as classes populares. Nesses espaços elas aparecem como figuras centrais e atuantes, "enquanto que em outras áreas do noticiário jornalístico seu acesso é impossível ou secundário” (Serra, 1980:19).

Cotidianamente, os meios de comunicação nos fazem crer que se a grande massa excluída de nossa população age diferentemente das elites é porque vive e, portanto, pensa, percebe e sente diferentemente de nós. Daí, não podem receber o mesmo tratamento. 
Não é por acaso que, em vez de cidadão, a palavra mais freqüentemente utilizada hoje seja “consumidor". As políticas neoliberais, os 'mass-media' e demais equipamentos sociais produzem a confusão entre "direitos do cidadão" e "direitos do consumidor". O que mostra que só tem valor aquele que consome: os milhões de excluídos e miseráveis não são cidadãos, pois, por não consumirem, nada valem; são simples objetos.

Consumindo, o indivíduo se situa num tempo em que as esferas e os espaços públicos estão enquadrados pelos meios de comunicação e pela linguagem publicitária, o homem se contextualiza pelo consumo (...). Agora, na era da globalização, podemos dizer que a categoria de cidadão foi englobada pela categoria de consumidor (...), pois é exercendo sua condição de consumidor que o homem se reconhece cidadão (Bucci, 1997, p. 46).

Um dos efeitos desta falta de cidadania é a "culpabilização da vítima”. Ou seja, além da forma como são produzidos os "bandidos", os "marginais", os "criminosos" de todos os tipos, eles são ainda contruídos para se responsabilizam por sua miséria, marginaldade e criminalidade. No capitalismo, uma das mais competentes produções prende-se à individualização das responsabilidades - seja colocando na natureza humana, em sua história de vida ou em seu meio ambiente certos dons ou defeitos. O indivíduo passa a ser a medida de todas as coisas e o único responsável por suas vitórias ou fracassos ${ }^{9}$.

O segundo aspecto a ser levantado prende-se à justiça militar e perdura até hoje: o julgamento de crimes cometidos por policiais militares por membros da própria corporação. Em 1977 - durante o governo Geisel -, dentro dos dispositivos do chamado "pacote de abril", manteve-se que a Justiça Militar é que deveria julgar os crimes cometidos durante as atividades de policiamento. Mantém-se ainda uma visão militarizada da segurança pública, pois

o policiamento ostensivo e a prevenção da ordem pública, além de permanecerem militarizados, continuam a contar com o foro especial da justiça das polícias

9 Sobre o assunto, consultar Barros, R.D. B (1994). 
militares estaduais. Como durante o regime militar, tem ficado patente que essa justiça tem servido para proteger policiais em ações criminosas (Pinheiro, 1996, p. 28).

Este mesmo autor informa que tanto o Código Militar quanto o Código de Processo Penal Militar, voltados para as operações militares das Forças Armadas, não se encontram em condições de julgar e investigar crimes civis praticados durante ações de policiamento. Não somente falhas técnicas são apontadas, mas a questão da impunidade aí está colocada, pois de um modo geral as mortes praticadas por policiais militares são caracterizadas como homicídios justificáveis, em alegados confrontos.

Além dessas limitações corporativas e técnicas, diante do crescimento da criminalidade violenta, ações policiais têm aumentado e os efetivos policiais têm se expandido, o que contribui para agravar a precariedade do sistema de justiça das polícias militares estaduais: os processos concluídos diminuem, embora os casos tenham aumentado (...). Os processos estendem-se por muitos anos e durante esse tempo os policiais acusados continuam em serviço normalmente, podendo até receber elogios funcionais, promocionais e condecorações (Pinheiro, 1996, p. 29).

Em 1996, projeto de lei do deputado Hélio Bicudo restaurando a competência da justiça civil para julgar crimes de militares contra civis foi aprovado na Câmara dos Deputados, com bastantes restrições: limitou-se a homicídios, sendo que a investigação continuaria sob responsabilidade dos IPM's . No mesmo ano, o projeto, parcialmente aprovado na Câmara, foi derrubado no Senado Federal. Os próprios partidos que apoiavam o governo federal - que propunha o projeto de Hélio Bicudo no seu Plano Nacional de Direitos Humanos, anunciado ao país em 13 de maio de 1996 - aprovaram um substitutivo, segundo o qual só os crimes dolosos contra a vida, cometidos por militares contra civis, é que poderão ser julgados pela justiça comum. Na prática, nada muda no julgamento dos crimes cometidos por policiais militares.

A Comissão Interamericana de Direitos Humanos da Organização dos Estados Americanos (OEA), em sua visita ao Brasil, em dezembro de 
1995, a primeira que fez ao nosso país em toda a sua história, recomendava que

(...) seria positivo que crime cometido por militar fosse julgado pela Justiça Comum e não pela Justiça Militar, porque este tipo de Justiça tem alto índice de impunidade (Jornal do Brasil, 1995, p. 14)

Sabemos que a própria Constituição brasileira de 1988, apesar de alguns avanços referentes aos direitos individuais e sociais, manteve as polícias militares estaduais como força de reserva do Exército, a respeito do que o articulista Jânio de Freitas, no patamar do século XXI, afirma:

A deterioração das PM's foi o maior legado da 'política de segurança' da ditadura, que lhes alterou os critérios de seleção, a formação e a finalidade, para fazê-las 'forças auxiliares das Forças Armadas' na repressão política e social. Nada foi feito desde o fim do regime militar, para reparar o legado (Folha de S.Paulo, 2000, A5)

Por esses dois pequenos exemplos, vemos o quanto ainda hoje se mantêm em nosso país muitos dos aspectos repressivos e autoritários vigentes nos "anos de chumbo". Considero que entender, analisar e colocar em destaque tais questões é uma das tarefas, hoje, dos profissionais das chamadas Ciências Humanas e Sociais e, em especial, do profissional "psi”, que, de um modo geral, articula muito pouco sua prática com a História. A Psicologia, através de diferentes ferramentas, pode contribuir para um maior entendimento do que está sendo forjado cotidianamente através de uma série de dispositivos sociais, muitos deles remanescentes do período repressivo.

Penso, portanto, que tais temas sejam relevantes para o psicólogo que, de um modo geral, teve sua formação voltada para a produção/reprodução/fortalecimento de práticas algumas vezes intimistas, privatizantes, familiaristas e psicologizantes. Considero, com isso, que esse profissional pode e deve se voltar não somente para a nossa realidade, mas deve também utilizar suas ferramentas de trabalho no sentido de desconstruir o que é percebido como natural, como essência do ser humano. Pode, portanto, concorrer para apontar a violência e seus 
efeitos, que hoje dominam a todos nós, em especial nos grandes centros urbanos brasileiros, não como um dado de nossa natureza ou de nossa sociedade, mas como uma produção histórico-social, datada, localizável e com ramificações vindas de nossa História recente.

\section{REFERÊNCIAS BIBLIOGRÁFICAS}

Arquidiocese de São Paulo (1985a). Em Projeto Brasil nunca mais (Tomo I, O regime militar). São Paulo: Arquidiocese de São Paulo.

Arquidiocese de São Paulo (1985b). Em Projeto Brasil nunca mais (Tomo IV, As leis repressivas). São Paulo: Arquidiocese de São Paulo.

Arquidiocese de São Paulo (1985c). Em Projeto Brasil nunca mais (Tomo V, volume 1, As torturas). São Paulo: Arquidiocese de São Paulo.

Baratta, A. (1993). O filósofo de uma criminologia crítica. Em Governo Estadual do Rio de Janeiro (Org.), Mídia \& violência (pp. 10-23) Rio de Janeiro: Fundação de Amparo à Pesquisa do Estado do Rio de Janeiro.

Barros, R. D. B. (1994). Grupo: a afirmação de um simulacro. Tese de Doutorado, Pontifícia Universidade Católica, São Paulo.

Bucci, E. (1997). Sociedade de consumo (ou consumo de preconceito). Em Secretaria da Justiça e Cidadania de São Paulo. O preconceito (pp. 32-52). São Paulo.

Coimbra, C. M. B. (1995). Guardiães da ordem: uma viagem pelas práticas "psi" no Brasil do "milagre ". Rio de Janeiro : Oficina do Autor.

Coimbra, C. M. B. (1998) - Discursos sobre segurança pública e produção de subjetividade: violência urbana e alguns de seus efeitos. Trabalho de PósDoutorado. Núcleo de Estudos da Violência. Universidade de São Paulo, São Paulo.

Folha de S.Paulo (2000). São Paulo, Caderno A, p. 5, outubro.

Guatari, F. \& Rolnik, S. (1988). Micropolítica: cartografias do desejo. Rio de Janeiro: Vozes.

Hollanda, H. B. (1978). Impressões de viagem. Tese de Doutorado, Universidade Federal do Rio de Janeiro, Rio de Janeiro.

Ianni, O. (1968). O colapso do populismo no Brasil. Rio de Janeiro: Civilização Brasileira.

Jornal do Brasil (1995). Rio de Janeiro, Caderno 1, p. 14, dezembro.

Jornal da Tarde (1973). São Paulo, Caderno A, p. 10, setembro.

Mariano, N. C. (1998) Operación Condor: terrorismo de estado en el Cono Sur. Buenos Aires: Lohlé - Lúmen. 
Pinheiro, P. S. (1996). O Passado Não Está Morto: nem passado ainda é. Em Dimenstein, G. (Org.), Democracia em pedaços (pp. 10-30). São Paulo: Cia das Letras.

Reis Filho, D. A. (1988) 1968: a utopia de uma paixão. Rio de Janeiro: Espaço e Tempo.

Schwarz, R. (1978). O pai de família e outros estudos. Rio de Janeiro: Paz e Terra.

Serra, A. A. (1980). O desvio nosso de cada dia : a representação do cotidiano num jornal popular. Rio de Janeiro: Achiamé.

Silva, G. C.(1967). Geopolítica do Brasil. Rio de Janeiro: José Olympio.

Ventura, Z. (1988). 1968: o ano que não terminou. Rio de Janeiro: Nova Fronteira.

Recebido em 28/07 /00

Revisado em 25/11/00

Aceito em 01/12/00 